\title{
IMPLEMENTAÇÃO EM LINGUAGUEM PYTHON DE MÉTODOS DE ESTIMAÇÃO E COMPAPARAÇÃO DE PARÂMETROS CINÉTICOS APLICADO A HIDRÓLISE CATALISADA POR ALDC
}

\author{
A. S. PEREIRA ${ }^{1}$, J. B. M. NETO ${ }^{1}$, C. M. G. FARIAS $^{1}$ e L. R. B. GONÇALVES ${ }^{1}$ \\ ${ }^{1}$ Universidade Federal do Ceará, Departamento de Engenharia Química \\ E-mail para contato: $\operatorname{lrg} @$ ufc.com
}

\begin{abstract}
RESUMO - A enzima $\alpha$-acetolactato descarboxilase (ALDC) é amplamente utilizada no processo cervejeiro, aumentando a eficiência da fermentação e convertendo $\alpha$-acetolactato diretamente em acetoína, reduzindo assim a formação de diacetil que é um produto indesejável por alterar algumas características organolépticas. O estudo laboratorial permite a determinação dos parâmetros cinéticos através do método diferencial que leva em consideração a velocidade inicial da formação do complexo enzima-substrato, onde a concentração desse substrato irá influenciar na velocidade máxima da reação de catálise (Vmáx) e na constante de Michaelis-Menten (Km). Este trabalho tem como objetivo desenvolver um programa em ambiente de programação IPython Notebook, para obtenção e comparação dos parâmetros cinéticos da reação. Para demonstração, estes parâmetros foram estimados para ALDC, através das equações proposta por: Lineweaver-Burk, Eisenthal e Cornish-Bowden e Michaelis-Menten.
\end{abstract}

\section{INTRODUÇÃO}

O estudo da cinética enzimática permite compreender as reações químicas catalisadas por enzimas, assim como o mecanismo catalítico, o metabolismo enzimático e seus tipos de inibições. Algumas das finalidades são medir as velocidades das transformações, estudar a influência nas condições de trabalho, otimizar processos e projetar reatores adequados para cada reação. Para isso, faz-se necessário a determinação dos parâmetros enzimáticos: velocidade máxima da reação $\left(\mathrm{V}_{\text {máx }}\right)$ e da constante de Michaelis-Menten $\left(\mathrm{K}_{\mathrm{m}}\right)$.

Existem vários métodos de estimar esses parâmetros, variando-se a concentração de substrato [S] nas reações enzimáticas. Neste trabalho, desenvolveu-se um programa implementado em linguagem científica Python e seus módulos, que utiliza o modelo de Michaelis-Menten e os métodos de linearização proposta por Lineweaver-Burke e por Eisenthal e Cornish-Bowden para estimar os valores de $\mathrm{V}_{\text {máx }}$ e $\mathrm{K}_{\mathrm{m}}$.

Em caráter demonstrativo do programa desenvolvido, escolheu-se estudar a cinética da enzima $\alpha$-acetolactato descarboxilase (ALDC) muito importante para indústria cervejeira por diminuir o tempo de maturação e assim aumentar a produtividade industrial. A ALDC gera uma conversão direta de $\alpha$-acetolactato em acetoína, que provoca uma redução no tempo de 


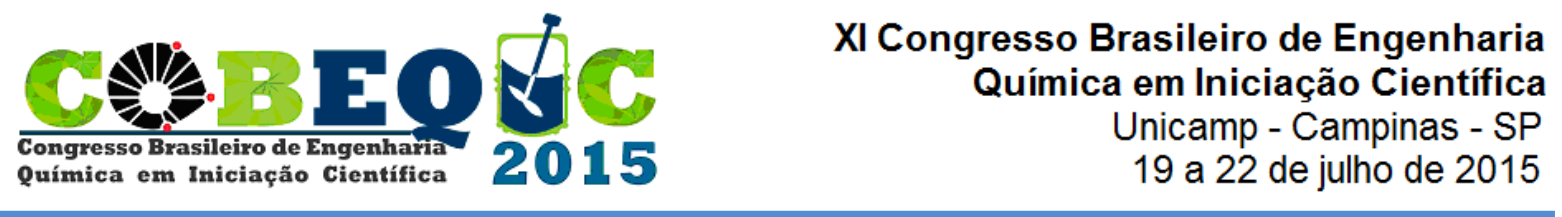

reação, evitando a necessidade de maturação secundária de diacetil para acetoína. A formação do diacetil pela descarboxilação oxidativa do $\alpha$-acetolactato, processo lento e não-enzimático, confere a bebida sabor amanteigado que afeta a qualidade do produto.

\section{METODOLOGIA}

\subsection{Materiais}

Substrato: etil-2-acetoxi-2-metilacetolactato.

Enzima: $\alpha$-acetolactato descarboxilase (solução com concentração de proteína de 2,677 $\mathrm{mg} / \mathrm{ml} \mathrm{a} 30^{\circ} \mathrm{C}$ e $\mathrm{pH}$ de 6,0$)$.

\subsection{Métodos}

Procedimento experimental: Utilizou-se o método diferencial, que leva em consideração a velocidade inicial da reação $\left(\mathrm{V}_{0}\right)$ e permite desprezar a reação inversa, caso seja reação reversível. Para determinar a atividade da enzima ALDC, empregou-se o procedimento modificado estabelecido por Stormer (1975). Adicionou-se a uma amostra de 5 $\mu \mathrm{L}$ de enzima, em $95 \mu \mathrm{L}$ de tampão MES $50 \mathrm{mM}, 200 \mu \mathrm{L}$ de solução de substrato. Repetiu-se esse procedimento para diferentes concentrações de substrato, medindo-se a atividade enzimática após 40 min de reação. Uma unidade (U) de ALDC foi definida como sendo a quantidade de enzima para liberar $1 \mu \mathrm{mol}$ de acetoína/min $\left(\mathrm{V}_{0}\right)$ nas condições analisadas.

Método numérico: As equações dos modelos matemáticos foram resolvidas numericamente através de programa implementado em linguagem Python/IPython Notebook associada a alguns de seus módulos científicos e os gráficos gerados são apresentados nesse trabalho. Observou-se que os dados experimentais se ajustam muito bem ao modelo proposto por Michaelis-Menten, certificando o trabalho de Dulieu et al. (2000).

\section{MODELOS MATEMÁTICOS}

\subsection{Cinética de Michaelis-Menten}

Michaelis e Menten (1913) propuseram que a formação do complexo enzima-substrato é reversível e que o reaparecimento da enzima livre e a formação do produto, segunda etapa, é irreversível e o passo mais lento neste modelo. A Equação 1 relaciona quantitativamente a constante de Michaelis-Menten $\left(\mathrm{K}_{\mathrm{m}}\right)$, a velocidade inicial $\left(\mathrm{V}_{0}\right)$, a velocidade inicial máxima $\left(\mathrm{V}_{\text {máx }}\right)$ e a concentração inicial de substrato $[\mathrm{S}]$ descrita por estes pesquisadores.

$$
V_{0}=\frac{V_{m a ́ x}[S]}{K_{m}+[S]}
$$

De forma simples, o valor de $\mathrm{K}_{\mathrm{m}}$ é interpretado como a afinidade enzima-substrato, e quanto menor seu valor maior a afinidade entre o complexo. É importante lembrar que a $V_{\text {máx }}$ não é constante, depende da concentração da enzima utilizada nos experimentos. 


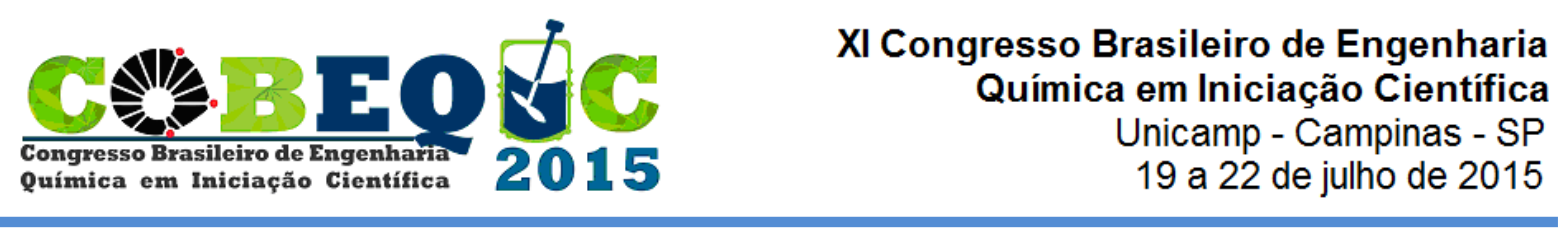

\subsection{Linearização por Lineweaver-Burk}

A Equação 2 proposta por Lineweaver e Burk (1934), também conhecida como duplo recíprocos, é obtida pela inversão da Equação 1 de Michaelis-Menten. $\mathrm{O}$ gráfico de $1 / \mathrm{V}_{0}$ versus $1 /[\mathrm{S}]$ será representado por uma reta, onde: o coeficiente angular é igual a $\mathrm{K}_{\mathrm{m}} / \mathrm{V}_{\text {máx }}$ e o coeficiente linear é igual a $1 / \mathrm{V}_{\text {máx. }}$

$$
\frac{1}{V_{0}}=\frac{K_{m}}{V_{\text {máx }}[S]}+\frac{1}{V_{\text {máx }}}
$$

Este método de linearização é muito utilizado para testar qualitativamente o mecanismo da reação proposta, mas não é adequado para se estimar os parâmetros cinéticos por intensificar o erro experimental da concentração do substrato e da velocidade inicial da reação, por ser necessário aplicar o inverso dos valores no modelo.

\subsection{Linearização por Eisenthal e Cornish-Bowden}

No método proposto por Cornish-Bowden e Eisenthal (1974), a equação de MichaelisMenten é expressa em forma de proporção, Equação 3. Como pode ser observado na Figura 1, para qualquer triangulo retângulo de catetos $\mathrm{V}_{\mathrm{i}} \mathrm{e}[\mathrm{S}]_{\mathrm{i}}$, terá um triangulo semelhante de catetos $\mathrm{V}_{\text {máx }}$ e $[\mathrm{S}]_{\mathrm{i}}+\mathrm{K}_{\mathrm{m}}$, respectivamente. Isso significa que todas as retas que forem traçadas passando por $\mathrm{V}_{\mathrm{i}}$ e $[\mathrm{S}]_{\mathrm{i}}$ e que obedecerem o modelo de Michaelis-Menten, se cruzaram em um único ponto de coordenadas $\mathrm{V}_{\text {máx }}$ e $\mathrm{k}_{\mathrm{m}}$, como afirma Pinto e Menezes (2009).

$$
\frac{V_{0}}{[S]}=\frac{V_{m a ́ x}}{K_{m}+[S]}
$$

Figura 1 - Gráfico de Eisenthal e Cornish-Bowden. Fonte: Chaplin e Bucke (1990).
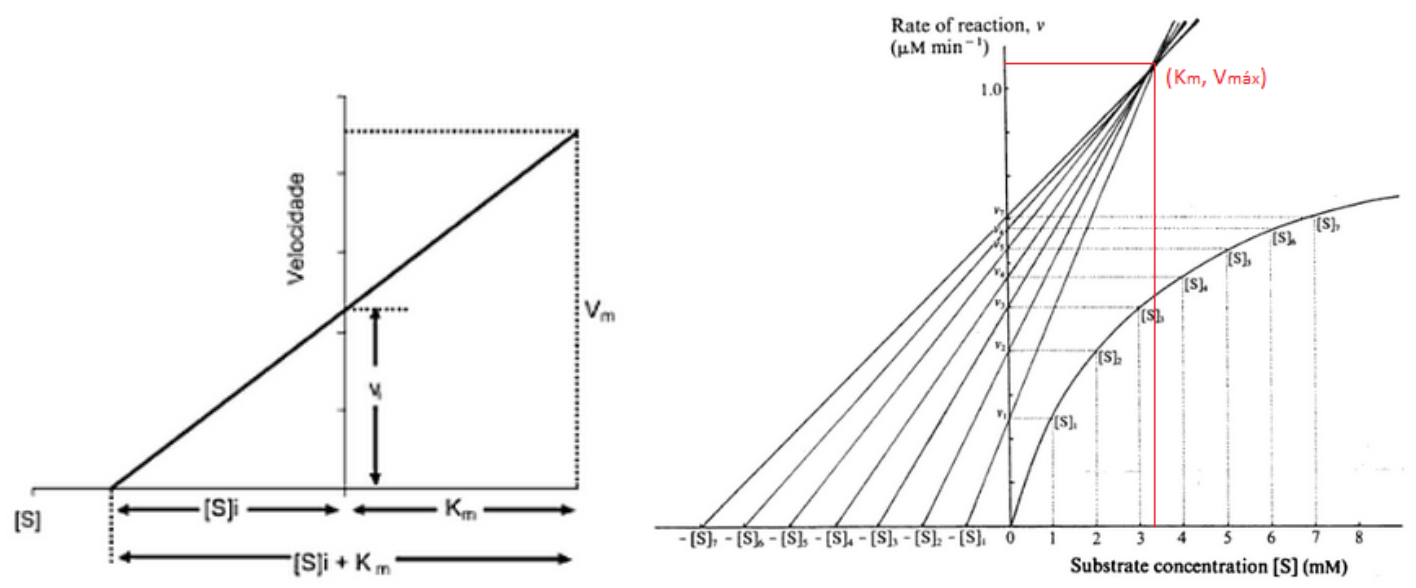

As equações a seguir mostram a forma matemática desenvolvida neste trabalho para simular a linearização por Eisenthal e Cornish-Bowden, método gráfico. Dessa forma, podese determinar o coeficiente angular para cada reta e substituir o ponto $\left(0, \mathrm{~V}_{\mathrm{i}}\right)$, obtendo-se assim todas as retas e consequentemente os parâmetros cinéticos. 


$$
\begin{aligned}
& m=\frac{\Delta y}{\Delta x}=\frac{V_{i}-0}{0-\left(-[S]_{i}\right)}=\frac{V_{i}}{[S]_{i}} \\
& y=\frac{V_{i}}{[S]_{i}} x+V_{i}
\end{aligned}
$$

A existência de erros experimentais introduzidos na determinação de $\mathrm{V}_{\mathrm{i}}$ e $[\mathrm{S}]_{\mathrm{i}}$ fazem com que as retas não se cruzem em um único ponto. A melhor estimativa para os parâmetros cinéticos é através de um tratamento estatístico, onde se utiliza a mediana dos pontos de intersecção, sendo o mais preciso dos métodos apresentados neste trabalho por não ser influenciado pelos pontos anômalos. Isso não acontece para modelos que utilizam o método dos mínimos quadrados para obtenção dos parâmetros cinéticos, mostrado por Cornish-Bowden e Endrenyi (1981).

\section{RESULTADO E DISCUSSÃO}

A tabela 1 mostra a relação entre as variações das concentrações de substrato e as velocidades iniciais obtidas. As simulações apresentadas neste trabalho foram realizadas na ferramenta computacional livre Python e seus módulos, onde a implementação dos modelos foram validados de forma indireta pelo software gráfico, para análise de dados, Origin.

Tabela 1- Dados experimentais.

\begin{tabular}{lrrrrrr}
\hline$[\mathrm{S}](\mathrm{mol} / \mathrm{L})$ & 0,01 & 0,02 & 0,04 & 0,06 & 0,08 & 0,1 \\
$\mathrm{~V}_{0}(\mathrm{~mol} / \mathrm{L})$ & 0,323 & 0,579 & 0,748 & 0,862 & 0,91 & 0,991 \\
\hline
\end{tabular}

A Figura 2 traz o assuste dos modelos de Michaelis-Menten e de Lineweaver-Burk utilizando o método dos mínimos quadrados. Como apresentado ao longo deste trabalho, ambos levam em consideração os erros experimentais anômalos, que acabam prejudicando o ajuste dos parâmetros cinéticos.

Figura 2 - Ajuste por mínimos quadrados: (a) Michaelis-Menten e (b) Lineweaver-Burk.

(a)

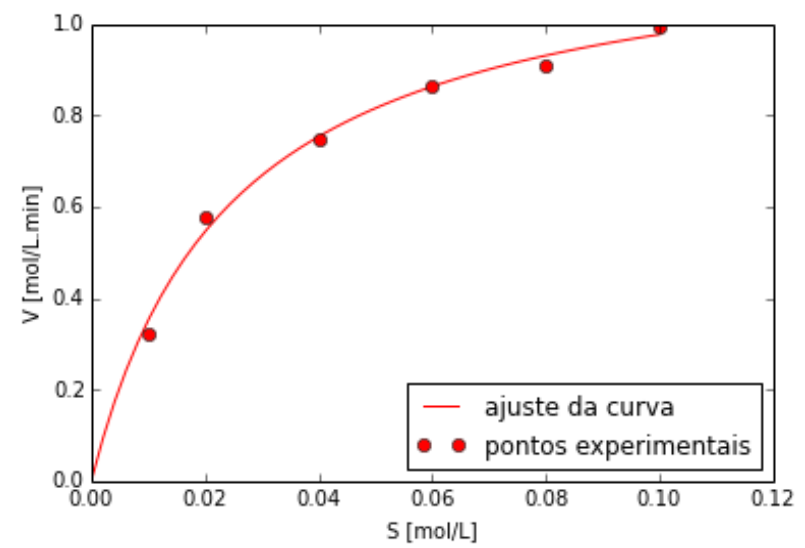

(b)

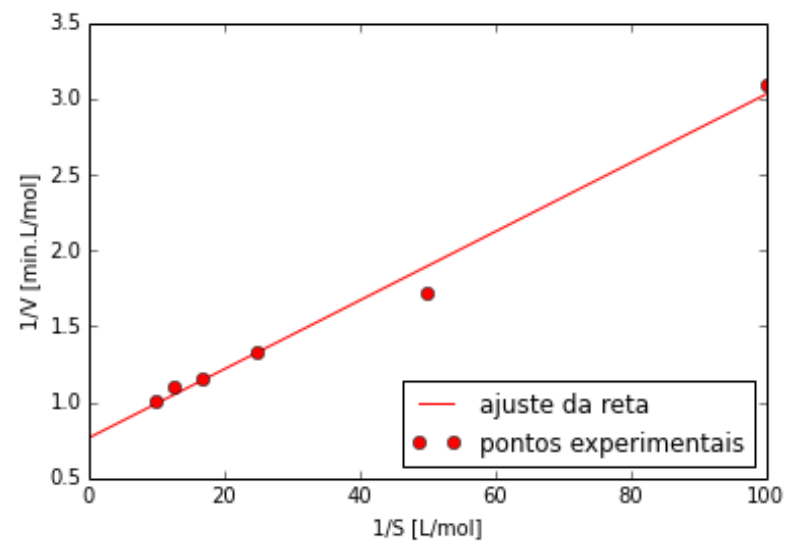

Na Figura 3 foi utilizado o modelo de Cornish-Bowden e Eisenthal, e observa-se a existência de pontos experimentais com erros aleatórios. Como este método permite um tratamento estatístico, faz-se necessário todos os valores das intersecções das retas. Esses 
valores foram obtidos de forma analítica, utilizando o Python, e ordenados de forma crescente na Tabela 2, utilizando a Equação 6 para determinar todas as combinações sem repetições possíveis, onde: $\mathrm{n}=$ números de pontos experimentais e $\mathrm{p}=$ números de parâmetros. Pinto $\mathrm{e}$ Menezes (2009).

(6)

$$
N=\frac{n !}{p ! .(n-p) !}=\frac{6 !}{2 ! .(6-2) !}=15 \text { interseções possíveis }
$$

Figura 3 - (a) Linearização de Cornish-Bowden e Eisenthal; (b) Ampliação do gráfico.

(a)

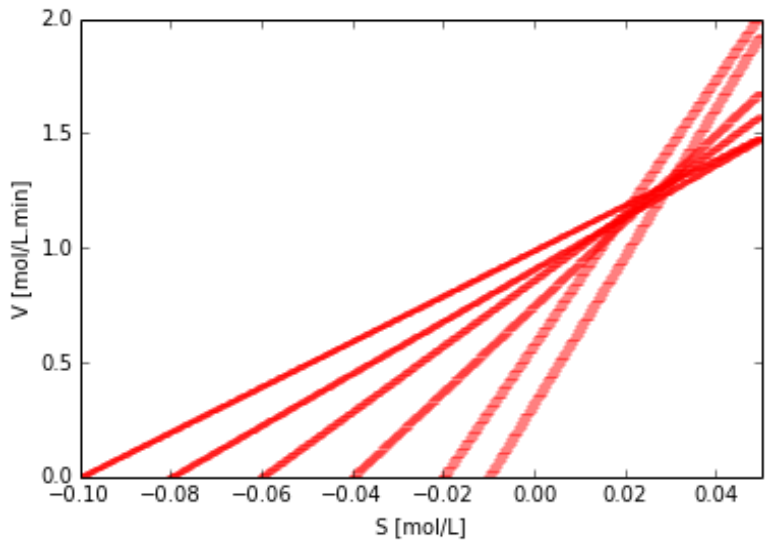

(b)

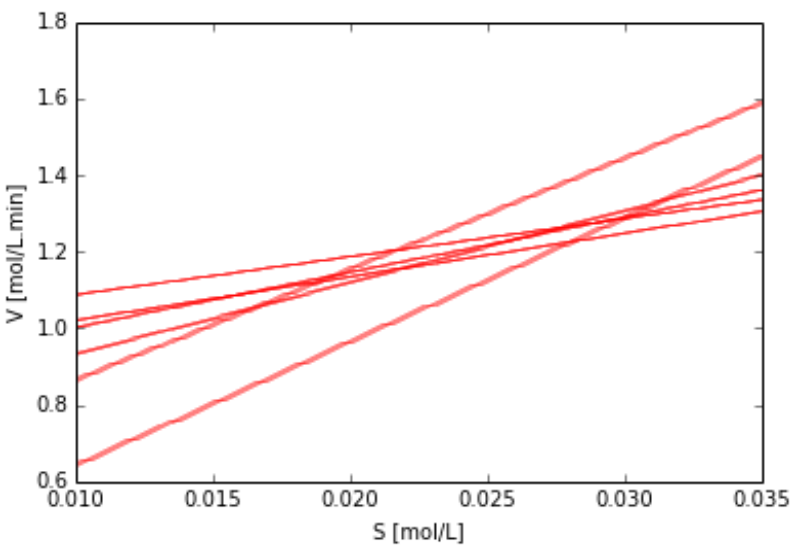

Tabela 2 - Valores crescentes das intersecções das retas de Cornish-Bowden e Eisenthal.

\begin{tabular}{ccccccccc}
\hline $\mathrm{V}_{0}$ & 11.560 & 11.784 & 11.842 & 12.066 & 12.107 & 12.522 & 12.522 & 12.663 \\
$(\mathrm{~mol} / \mathrm{L})$ & 12.696 & 12.820 & 12.878 & 12.895 & 13.027 & 15.518 & 17.519 & \\
\hline$[\mathrm{S}]$ & 0.0199 & 0.0207 & 0.0209 & 0.0216 & 0.0247 & 0.0269 & 0.0271 & 0.0276 \\
$(\mathrm{~mol} / \mathrm{L})$ & 0.0292 & 0.0293 & 0.0299 & 0.0299 & 0.0303 & 0.0442 & 0.0565 & \\
\hline
\end{tabular}

A mediana dos pontos de intersecção são $\mathrm{V} 0=1,2663 \mathrm{~mol} / \mathrm{L} \cdot \mathrm{min}$ e $[\mathrm{S}]=0,0276 \mathrm{~mol} / \mathrm{L}$, que representa o valor da velocidade inicial máxima da reação e constante de MichaelisMenten, respectivamente. Dessa forma, o modelo de Cornish-Bowden e Eisenthal é o mais preciso por não levar em consideração os dados experimentais anômalos.

Percebe-se pela Tabela 3 e Figura 4, que os desvios de Michaelis-Menten e Lineweaver-Burk são muito pequenos para o ajuste dos parâmetros cinéticos da ALDC, mostrando que qualquer dos três modelos poderia ser utilizados sem grandes erros.

Figura 4 - Comparação dos modelos. 

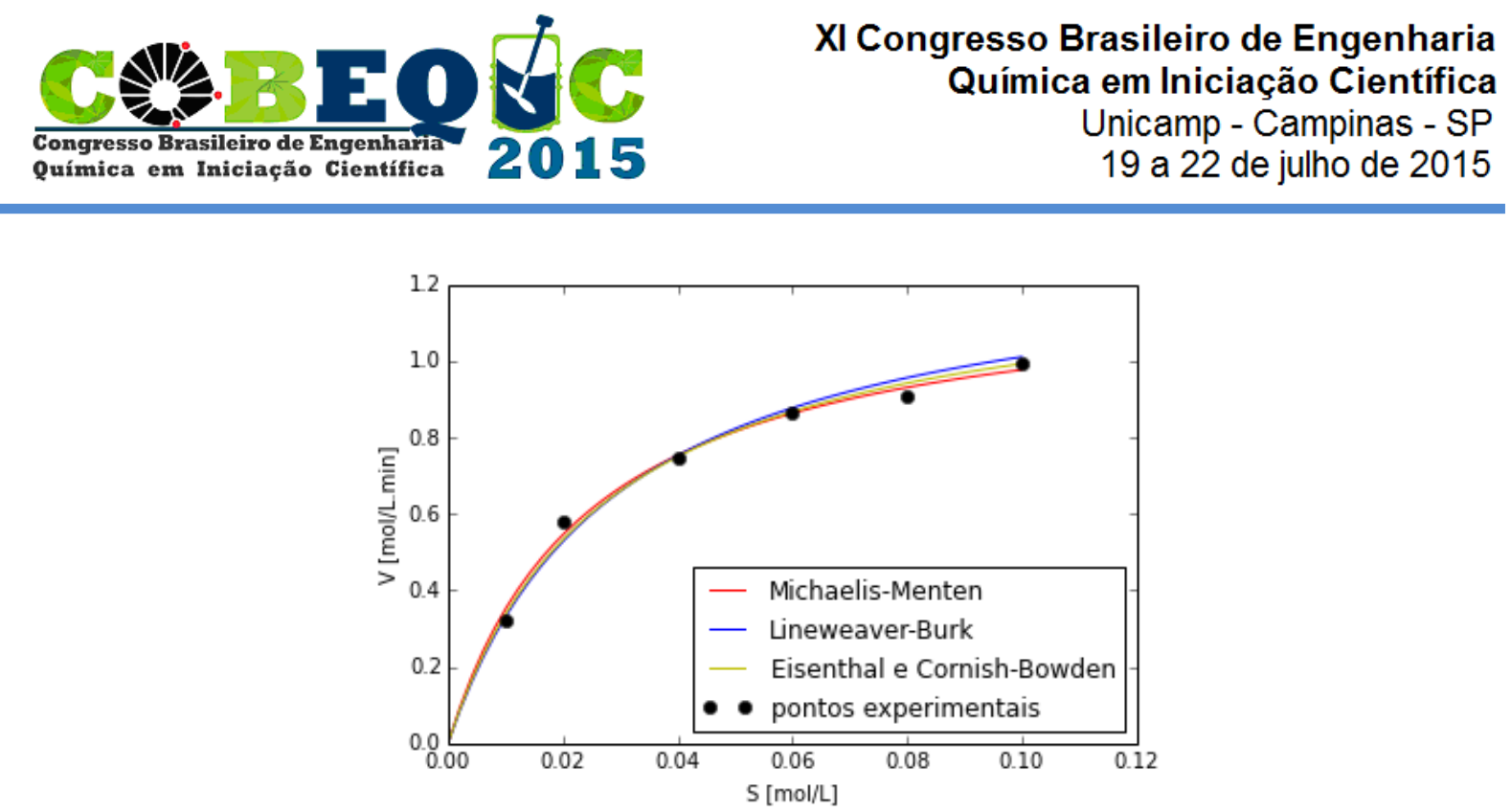

Tabela 3 - Resumo dos parâmetros cinéticos para cada modelo apresentado.

\begin{tabular}{cccc}
\hline & Michaelis-Menten & Lineweaver-Burk & Eisenthal e Cornish-Bowden \\
\hline $\mathrm{V}_{\text {máx }}(\mathrm{mol} / \mathrm{L} . \mathrm{min})$ & 12.171 & 13.098 & 12.663 \\
$\mathrm{~K}_{\mathrm{m}}(\mathrm{mol} / \mathrm{L})$ & 0.0247 & 0.0296 & 0.0276 \\
\hline
\end{tabular}

\section{CONCLUSÃO}

A cinética enzimática é essencial pra compreender o mecanismo catalítico, o metabolismo enzimático e seus tipos de inibições. Com isso, percebe-se a importância de determinar os parâmetros cinéticos, $\mathrm{V}_{\text {máx }}$ e $\mathrm{K}_{\mathrm{m}}$.

Neste trabalho, implementou-se três modelos de estimação desses parâmetros utilizando o Python/IPython Notebook associada a alguns de seus módulos científicos. O código desenvolvido estima os parâmetros cinético, simula comportamento, apresenta gráficos e compara modelos de forma muito simples para o usuário.

\section{REFERENCIAS}

CORNISH-BOWDEN, A.; ENDRENYI, L.; Fitting of enzyme Kinect data without prior knowledge of weights. Biochem. J., v. 193, p. 1005-1008, 1981.

CHAPLIN, M. F.; BUCKE, C. Enzyme Tecnology. Cambridge: Cambridge University, 1990.

DULIEU, C.; MOLL, M.; BOUDRANT, J.; PONCELET, D.; Improved Performances and Control of Beer Fermentation Using Encapsulated $\alpha$-Acetolactato Descarboxylase and Modeling. Biotechnol. Prog. 2000.

EISENTHAL, R.; CORNISH-BOWDEN, A.; The direct linear plot. Biochem. J., v. 139, p. 715-20, 1974.

LINEWEAVER, H.; BURK, D.; The determination of enzyme dissociation constants. $J \mathrm{Am}$ Chem Soc, v. 56, p. 658-666, 1934. 
MICHAELIS, L.; MENTEN, M.L.; The kinetics of invertin action. Biochem. Z. v. 49, p. 33369, 1913.

PINTO, G. F.; MENEZES, R. R. Cinética enzimática. Rio de Janeiro: E-papers Serviços Editoriais Ltda, 2009.

STORMER, F. C. Methods in Enzymology, XLI, p. 526-529, 1975. 